\title{
Spatial-Temporal Analysis of the Economic and Environmental Coordination Development Degree in Liaoning Province
}

\author{
Hui Wang, ${ }^{1,2}$ Fan Liu, ${ }^{2}$ Ying Yuan, ${ }^{2}$ and Liang Wang ${ }^{1}$ \\ ${ }^{1}$ School of Urban \& Environment, Liaoning Normal University, Dalian 116029, China \\ ${ }^{2}$ School of History \& Tourism, Liaoning Normal University, Dalian 116081, China \\ Correspondence should be addressed to Hui Wang; wanghuiouki@126.com
}

Received 6 February 2013; Revised 12 April 2013; Accepted 28 May 2013

Academic Editor: Tonny J. Oyana

Copyright (c) 2013 Hui Wang et al. This is an open access article distributed under the Creative Commons Attribution License, which permits unrestricted use, distribution, and reproduction in any medium, provided the original work is properly cited.

\begin{abstract}
This study selects 20 indices of economic and environmental conditions over 15 years (1996-2010) for 14 cities in Liaoning province, China. We calculate the economic score $F$ and environmental score $G$ of each city by processing 4200 data points through SPSS 16.0 and establish synthesis functions between the economy and the environment. For the time dimension, we study the temporal evolution of the economic and environmental coordination development degree $\left(D_{\mathrm{EECD}}\right)$. Based on Exploratory Spatial Data Analysis (ESDA) techniques and using GeoDa, we calculate Moran's index of local spatial autocorrelation and explore the spatial distribution character of $D_{\mathrm{EECD}}$ in Liaoning province through a LISA cluster map. As we found in the temporal dimension, the results show that $D_{\mathrm{EECD}}$ of the 14 cities has been rising for 15 years and that $D_{\mathrm{EECD}}$ increases year by year, which indicates that the economic and environmental coordination development condition has been improving from disorder to highly coordinated. A smaller gap between economic strength and environmental carrying capacity in Liaoning province exists, which means that economic development and environmental protection remain synchronized. In the spatial dimension, the highly coordinated cities have changed from a scattering to a concentration in the middle-south region of Liaoning province. Poorly coordinated cities are scattered in the northwestern region of Liaoning province.
\end{abstract}

\section{Introduction}

With the rapid pace of industrialization and urbanization in Liaoning province, the growing problems of urban environmental pollution and ecological destruction have become more serious. The joint desires of economic development and improving environmental quality have become seemingly incompatible. How to coordinate economic growth with environmental protection has become a focus of national attention and academic research.

In previous studies, both quantitative and qualitative, on the coordination degree between the economy and environment $\left(C_{\mathrm{EE}}\right)$ and the economic and environmental coordination development degree $\left(D_{\mathrm{EECD}}\right)$ [1-4], Yang [5] use the coordination degree $C$ as a quantitative indicator to measure the harmonizing degree of systems or factors. Wang and Jiang [2] find that the coordinated development degree $D$ measures the interactive coupling development degree of systems or factors and that $D$ reflects the overall coordinated development of systems or factors, which includes systems' or factors' coordination conditions (viz. C) as well as the development level. Wang et al. [6] emphasize that $D_{\mathrm{EECD}}$ determines the sustainability state of regional development and is important for judging whether regional development is healthy or not. However, almost all of them $[7,8]$ focus on the temporal dimension to measure and evaluate $D_{\mathrm{EECD}}$. Fewer studies analyze the interurban relationship of $D_{\mathrm{FECD}}$. Therefore, it is crucial and urgent to use a geographic method to evaluate and analyze $D_{\mathrm{EECD}}$ from a spatial dimension.

According to the first law of geography, the values of geographic variables in neighboring locations may be more similar or less similar than expected for randomly distributed locations [9], which means that the observations are commonly spatially dependent (spatial autocorrelation; [10]). Exploratory Spatial Data Analysis (ESDA) is a kind of SDA technology and a space analysis method that includes a series of techniques and tools including spatial autocorrelation coefficients and spatial statistics [11]. Spatial autocorrelation 
analysis can measure the degree of spatial agglomeration [12]. According to the scale of analyzed space, it can be divided into global spatial autocorrelation and local spatial autocorrelation. Yin and Kong [13] used the ESDA technology to analyze the spatial and temporal intercounty economic differences of China.

This study uses the ESDA technology to analyze interurban differences of $D_{\mathrm{EECD}}$ and its spatial distribution for Liaoning province from 1996 to 2010, the variations of local spatial autocorrelation. In short, this study aims to estimate the economic and environmental coordinated development condition of 14 cities in temporal and spatial dimensions. We also expect this study to offer a preliminary discussion on solving the contradictory problems between economic development and improving environmental quality.

\section{Methodologies}

2.1. Study Area. Located in the northeast economic zone and the Bohai sea economic circle, Liaoning province $\left(38^{\circ} 43^{\prime}\right.$ $43^{\circ} 26^{\prime} \mathrm{N}, 118^{\circ} 53^{\prime}-125^{\circ} 46^{\prime} \mathrm{E}$ ) has a solid heavy industry foundation and a long history. Since the introduction of Chinese economic reform, the Liaoning economy has experienced rapid growth, with resource and energy demand increasing constantly. Constraints between resources and the environment have become a significant bottleneck to the economic development of Liaoning province [14]. The $D_{\mathrm{EECD}}$ of Liaoning province not only measures the revitalization of old industrial bases and regional sustainable development in northeast China, but also includes China's opening to the outside world. This study considers 14 cities of Liaoning province (Figure 1), including Shenyang, Dalian, Anshan, Fushun, Benxi, Dandong, Jinzhou, Yingkou, Fuxin, Liaoyang, Panjin, Tieling, Chaoyang, and Huludao (although Fushun and Tieling belonged to Shenyang city in 2011, this paper considers them separately), from 1996 to 2010. The economic data and environmental data were obtained from statistical yearbooks (1997-2011) and statistical communiques.

\subsection{Data}

2.2.1. Index System. The heavy industry plays a leading role in the economic development of Liaoning province and also influences environment quality. Taking into account regions, data availability, and scientific evaluation, we select 20 indexes in 14 cities in Liaoning province during 1996-2010 [15].

The regional economic variables are GDP $\left(x_{1}\right), G D P$ per capita $\left(x_{2}\right)$, the proportion of the second industry $\left(x_{3}\right)$, the proportion of the service industry $\left(x_{4}\right)$, the growth rate of GDP $\left(x_{5}\right)$, the growth rate of the service industry $\left(x_{6}\right)$, the growth rate of fixed assets investments $\left(x_{7}\right)$, labor productivity of state-owned construction enterprises $\left(x_{8}\right)$, profit and tax on GDP above one million RMB $\left(x_{9}\right)$, and output value of the second industry above one hundred RMB of fixed assets $\left(x_{10}\right)$.

The regional environment variables are the emission of industrial $\mathrm{SO}_{2}\left(y_{1}\right)$, the emission of industrial dust $\left(y_{2}\right)$,

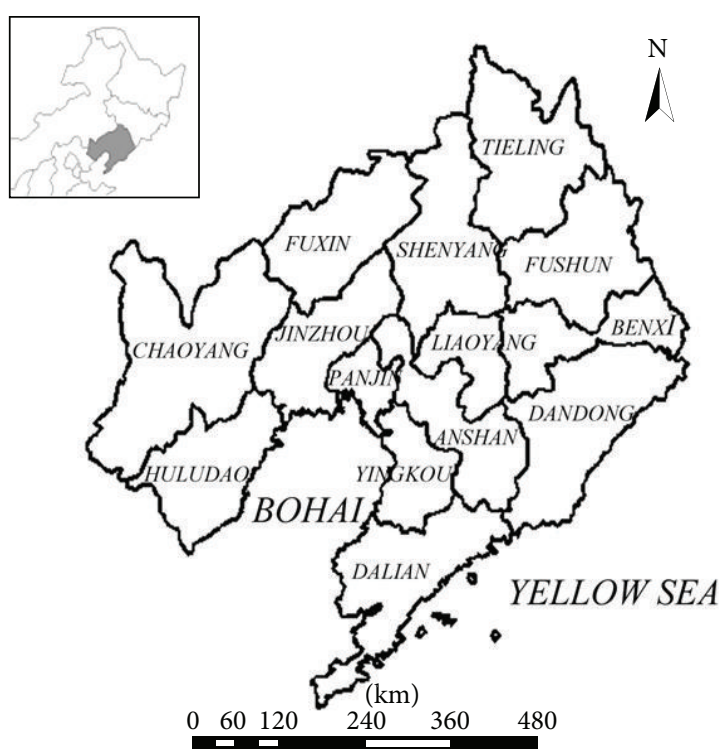

FIGURE 1: The scope and location of Liaoning province.

the emission of industrial effluent $\left(y_{3}\right)$, the quantity of industrial solid waste $\left(y_{4}\right)$, the standard area of environmental noise $\left(y_{5}\right)$, the processing emissions target rate of industrial effluent $\left(y_{6}\right)$, the rate of industrial solid waste comprehensive utilization $\left(y_{7}\right)$, pollution control fund/GDP $\left(y_{8}\right)$, greening coverage ratio in urban area $\left(y_{9}\right)$, and per capita public green land areas $\left(y_{10}\right)$.

2.2.2. Data Processing. When constructing the environment indexes, an "inverse index" is one where the smaller of the index is, the better over a certain range; while the higher value of "direct index", the better [16]. The following computational formula [17] is used to process the original data:

direct index:

$$
y_{i j}^{\prime}=\frac{y_{i j}-\min \left(y_{j}\right)}{\max \left(y_{j}\right)-\min \left(y_{j}\right)},
$$

inverse index:

$$
y_{i j}^{\prime}=\frac{\max \left(y_{j}\right)-y_{i j}}{\max \left(y_{j}\right)-\min \left(y_{j}\right)},
$$

where $y_{i j}^{\prime}$ is the standardized index; $y_{i j}$ is the measured value $j$ of index $i$; the way to process the economic index $x_{i j}^{\prime}$ is the same as that of direct index $y_{i j}^{\prime}$

2.3. Calculation of Coordination Development Degree. In order to achieve the "reduced dimension," we perform a principal component analysis of the economic and environmental indices for 14 cities using the statistical software SPSS16.0 and select the principal component factor, whose cumulative contribution rate is above $85 \%$. As a result, we obtain 
an economic principal component factor $F_{1}, F_{2}, \ldots, F_{m}$ and environmental principal component factor $G_{1}, G_{2}, \ldots, G_{n}$ and then normalize them.

According to the definition of coordination degree, we suppose $F_{1}, F_{2}, \ldots, F_{m}$ to describe the economic characteristics and $G_{1}, G_{2}, \ldots, G_{n}$ to describe the environmental characteristics. We then construct the synthesis functions of economy and environment as follows:

$$
\begin{aligned}
f(x)_{w}= & \frac{\lambda_{1}}{\lambda_{1}+\lambda_{2} \cdots+\lambda_{p}} F_{1 w}+\frac{\lambda_{2}}{\lambda_{1}+\lambda_{2} \cdots+\lambda_{p}} F_{2 w} \cdots \\
& +\frac{\lambda_{p}}{\lambda_{1}+\lambda_{2} \cdots+\lambda_{p}} F_{p_{w}} \\
g(y)_{w}= & \frac{\lambda_{1}}{\lambda_{1}+\lambda_{2} \cdots+\lambda_{p}} G_{1 w}+\frac{\lambda_{2}}{\lambda_{1}+\lambda_{2} \cdots+\lambda_{p}} G_{2 w} \cdots \\
& +\frac{\lambda_{p}}{\lambda_{1}+\lambda_{2} \cdots+\lambda_{p}} G_{p_{w}}
\end{aligned}
$$

where $f(x)_{w}$ denotes the economy synthesis functions for each city and $g(y)_{w}$ denotes the environment synthesis functions of each city. The values of $f(x)_{w}$ and $g(y)_{w}$ measure regional economic comprehensive strength and environmental capacity, respectively; $\lambda_{1}, \lambda_{2}, \ldots, \lambda_{p}$ indicates 1 th 2 th ...p pth principal component. (Characteristic value is above zero).

The coordination development degree calculation formula of Yang [18] is used in this paper:

$$
\begin{gathered}
C_{\mathrm{EE}}=\left\{\frac{f(x) \cdot g(y)}{[(f(x)+g(y)) / 2]^{2}}\right\}^{K}, \\
D_{\mathrm{EECD}}=\sqrt{C_{\mathrm{EE}} \cdot T}, \\
T=\alpha f(x)+\beta g(y),
\end{gathered}
$$

where $D_{\mathrm{EECD}}$ is the spatial autocorrelation coefficient of economic and environmental coordination development; $C_{\mathrm{EE}}$ is the coordination degree of the economy and environment; $K$ is an adjustment coefficient $K \geq 2$, in this paper, $K=2 ; T$ is a comprehensive evaluation index of economic and environmental effects (or development); $\alpha$ and $\beta$ are Pending weight; we assume that the degree of economy and environment development is coordinate, so $\alpha=\beta=0.5$.

Using these formulas, we calculate the coordination development degree of economic and environmental $D_{\text {EECD }}$ in Liaoning province (1996-2010), reported in Table 1.

2.4. Calculation of Spatial Autocorrelation. For spatial data with thematic attributes, spatial autocorrelation analysis techniques are frequently used [19], such as Moran's $I[20,21]$ and LISA [22]. To evaluate the spatial pattern of $D_{\mathrm{EECD}}$, local spatial autocorrelation analysis is conducted by calculating a common Moran's I tool supported by GeoDa. The spatial weight matrix uses the adjacency method. Local spatial autocorrelation analysis can reveal specific spatial patterns and find the location of spatially clustered and isolated regions [23]. The index adopted here reflects the spatial correlation of the $D_{\text {EECD }}$ distribution and is expressed as [24]

$$
I_{i}=\frac{\left(x_{i}-\bar{x}\right)}{s^{2}} \sum_{j=1 j \neq 1}^{n} W_{i j}\left(x_{j}-\bar{x}\right)=Z_{i} \sum_{j=1 j \neq 1}^{n} W_{i j} Z_{j},
$$

where $x_{i}$ and $x_{j}$ are values of the variable $x$ in two positions, $\bar{x}$ is the mean value of variable $x$, and $W_{i j}$ is the neighboring weight. $Z_{i}, Z_{j}$ is the standardization of attribute value in two positions, and $Z_{i}=\left(x-\bar{x}_{i}\right) / S, \sum_{j=1 i \neq i}^{n} W_{i j} Z_{j}$ is the space lag variable. The Moran index ranges from -1 to 1 . Generally, a high positive Moran index indicates a tendency towards clustering and an inclination to form larger assemblages in space. The closer the value is to 1 , the smaller the overall space difference is. A low negative Moran index indicates a tendency towards fragmentation and a tendency to scatter into smaller assemblages in space. If Moran's $I>0$, a region and its adjacent region do not have significant differences in space. In other words, the regions whose characteristic values are similar will be clustered ("High-High" or "Low-Low" clustering). If Moran's $I<0$, a region and its adjacent region have significant differences in space; the closer the value is to -1 , the bigger the overall space difference is. In these regions, characteristic values are dissimilar and clustering will be of the "Low-High" or "High-Low" variety. If Moran's $I=0$, spatial correlation does not exist. We calculate Moran's $I$ for Liaoning province (Table 2).

In order to test the null hypothesis of no spatial autocorrelation and conclude the Moran's I statistic is not significantly different from zero, this paper calculates the $t$-value using SPSS 16.0 statistical software. At a significance level of $P=$ 0.05 , we reject the null hypothesis when $-t<-0.05$ or $t>$ 0.05 [25]. We make the line chart (Figure 2) of Moran's $I$ and according to the temporal distribution of $D_{\mathrm{EECD}}$ disparities we chose eight extreme years (1996, 1997, 2000, 2002, 2004, 2005, 2007, and 2009), namely, the maximum or minimum point of spatial difference. In order to ensure the stability of the data, this paper combines a LISA significance level test with the $t$-value and makes a "Moran significance level figure" (meets $P=0.05$ significant test). After the significant level test, we get the new value points $(1996,1997,2000,2002,2004$, 2005 , and 2009) to use in a comparative study through the local spatial autocorrelation and LISA clustering map.

\section{Results and Discussion}

3.1. Temporal Analysis of $D_{E E C D}$. We classify the economic and environmental coordinated development condition of Liaoning province during 1996-2010 [5] according to the specifications in Table 3.

Based on the values of $D_{\mathrm{EECD}}$ (Table 1), we construct the evolutional trend of $D_{\mathrm{EECD}}$ in Liaoning province (1996-2010) (Figure 3).

(1) Overall, between 1996 to 2010, the economic and environmental coordinated development condition of Liaoning province has been rising continuously. Generally speaking, $D_{\mathrm{EECD}}$ rises gradually from 0.04 
TABLE 1: The coordination development degree of economy and environment in Liaoning province (1996-2010).

\begin{tabular}{ccccccccccccccccccc}
\hline & $\mathrm{a}$ & $\mathrm{b}$ & $\mathrm{c}$ & $\mathrm{d}$ & $\mathrm{e}$ & $\mathrm{f}$ & $\mathrm{g}$ & $\mathrm{h}$ & $\mathrm{i}$ & $\mathrm{j}$ & $\mathrm{k}$ & $\mathrm{l}$ & $\mathrm{m}$ & $\mathrm{n}$ & $\mathrm{o}$ \\
\hline 1996 & 0.00 & 0.00 & 0.00 & 0.00 & 0.00 & 0.09 & 0.00 & 0.32 & 0.00 & 0.00 & 0.00 & 0.03 & 0.00 & 0.10 & 0.04 \\
1997 & 0.11 & 0.37 & 0.00 & 0.00 & 0.24 & 0.00 & 0.33 & 0.00 & 0.27 & 0.30 & 0.24 & 0.00 & 0.16 & 0.00 & 0.14 \\
1998 & 0.00 & 0.50 & 0.17 & 0.19 & 0.45 & 0.14 & 0.39 & 0.00 & 0.38 & 0.26 & 0.46 & 0.00 & 0.15 & 0.32 & 0.24 \\
1999 & 0.47 & 0.39 & 0.34 & 0.39 & 0.46 & 0.00 & 0.38 & 0.22 & 0.43 & 0.38 & 0.39 & 0.33 & 0.32 & 0.08 & 0.33 \\
2000 & 0.47 & 0.61 & 0.49 & 0.49 & 0.67 & 0.31 & 0.19 & 0.29 & 0.44 & 0.50 & 0.00 & 0.39 & 0.42 & 0.00 & 0.38 \\
2001 & 0.49 & 0.70 & 0.46 & 0.48 & 0.70 & 0.45 & 0.00 & 0.32 & 0.59 & 0.00 & 0.34 & 0.48 & 0.00 & 0.21 & 0.37 \\
2002 & 0.68 & 0.81 & 0.57 & 0.52 & 0.31 & 0.50 & 0.35 & 0.35 & 0.69 & 0.51 & 0.40 & 0.47 & 0.42 & 0.41 & 0.50 \\
2003 & 0.77 & 0.78 & 0.70 & 0.66 & 0.79 & 0.56 & 0.52 & 0.43 & 0.66 & 0.70 & 0.50 & 0.63 & 0.52 & 0.76 & 0.64 \\
2004 & 0.87 & 0.90 & 0.77 & 0.73 & 0.93 & 0.61 & 0.54 & 0.67 & 0.79 & 0.82 & 0.61 & 0.76 & 0.60 & 0.83 & 0.74 \\
2005 & 0.86 & 0.97 & 0.97 & 0.80 & 0.93 & 0.70 & 0.56 & 0.87 & 0.82 & 0.79 & 0.60 & 0.84 & 0.72 & 0.67 & 0.79 \\
2006 & 0.91 & 0.92 & 0.85 & 0.77 & 0.72 & 0.75 & 0.74 & 0.82 & 0.94 & 0.83 & 0.54 & 0.85 & 0.93 & 0.75 & 0.81 \\
2007 & 0.93 & 0.97 & 0.83 & 0.84 & 0.74 & 0.80 & 0.80 & 0.89 & 0.86 & 0.87 & 0.75 & 0.84 & 0.96 & 0.81 & 0.85 \\
2008 & 0.92 & 0.96 & 0.95 & 0.90 & 0.86 & 0.76 & 0.87 & 0.96 & 0.90 & 0.80 & 0.77 & 0.90 & 0.97 & 0.91 & 0.89 \\
2009 & 0.93 & 0.94 & 0.97 & 0.91 & 0.88 & 0.84 & 0.87 & 0.95 & 0.96 & 0.83 & 0.97 & 0.86 & 0.96 & 0.87 & 0.91 \\
2010 & 0.99 & 0.97 & 1.00 & 0.96 & 0.91 & 1.00 & 1.00 & 0.97 & 0.96 & 0.95 & 0.99 & 0.88 & 0.95 & 0.93 & 0.96 \\
\hline
\end{tabular}

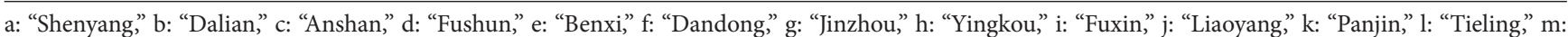
"Chaoyang," n: "Huludao," o: "Liaoning province."

TABLE 2: Moran's I of the coordination development degree between the economy and environment of Liaoning province (1996-2010).

\begin{tabular}{|c|c|c|c|c|c|c|c|c|c|c|c|c|c|c|c|}
\hline Year & 1996 & 1997 & 1998 & 1999 & 2000 & 2001 & 2002 & 2003 & 2004 & 2005 & 2006 & 2007 & 2008 & 2009 & 2010 \\
\hline$I$ & -0.18 & -0.26 & -0.23 & -0.09 & 0.17 & 0.062 & -0.09 & -0.11 & -0.11 & 0.13 & 0.025 & -0.13 & -0.04 & 0.079 & -0.03 \\
\hline
\end{tabular}

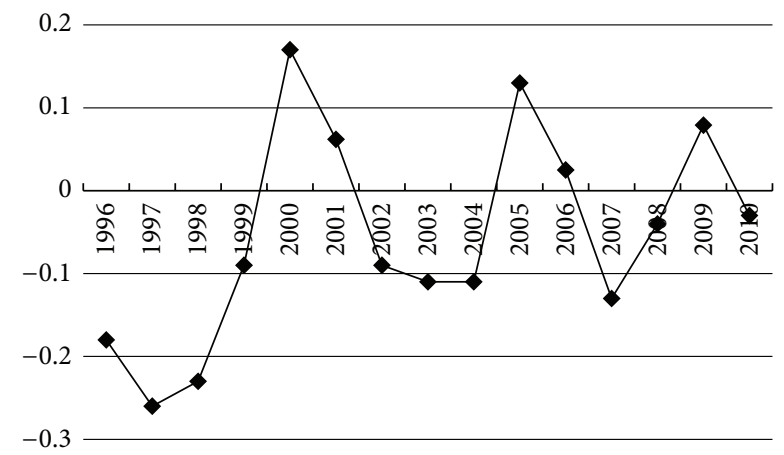

FIGURE 2: Moran's I of coordination degree of Liaoning province (1996-2010).

(1996) to 0.96 (2010). This indicates that the economic and environmental coordinated development of Liaoning province improves steadily from a serious disorder recession stage to a senior concordance development stage. During the "ninth five-year plan" period, the coordination development state between the economy and environment of Liaoning province belongs to disorder recession; during the "tenth fiveyear plan" period, the coordination development state between economy and environment of Liaoning province improves from the Low concordance development stage to the moderate concordance development stage. During the "eleventh five-year plan" period, the coordination development state between

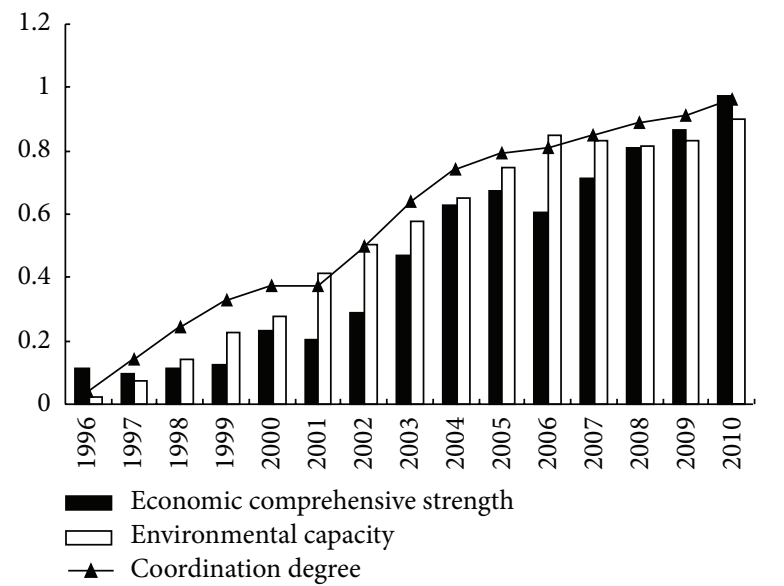

Figure 3: The evolutional trend of the coordination development degree between economy and environment in Liaoning Province (1996-2010).

economy and environment of Liaoning province advances to senior concordance development stage.

(2) Analyzing the difference between $f(x)_{w}$ and $g(y)_{w}$ between 1996 and 1997, $f(x)>g(y)$, which means that the economic development of Liaoning province is better than the environmental carrying capacity at this period. From 1998 to 2007, $f(x)<g(y)$ and in 2008, $f(x)=g(y)$, which means that the economic development of Liaoning province falls behind the environmental carrying capacity; 
TABle 3: The classification for $D_{\mathrm{EECD}}$ of Liaoning Province (1996-2010).

\begin{tabular}{lccc}
\hline & Value & Year & Type \\
\hline Coordinated development & $0.80 \leq D_{\mathrm{EECD}} \leq 1.00$ & $2006-2010$ & Senior concordance development \\
& $0.60 \leq D_{\mathrm{EECD}} \leq 0.79$ & $2003-2005$ & Moderate concordance development \\
Harmonic development & $0.40 \leq D_{\mathrm{EECD}} \leq 0.59$ & 2002 & Low concordance development \\
Disorder recession & $0.20 \leq D_{\mathrm{EECD}} \leq 0.39$ & $1998-2001$ & Moderate disorder recession \\
& $0<D_{\mathrm{EECD}} \leq 0.19$ & $1996-1997$ & Serious disorder recession \\
\hline
\end{tabular}

in other words, the economy can develop further within the environmental carrying capacity at this period, and the two almost develop synchronization in 2008. From 2009 to 2010, $f(x)>g(y)$ and $0 \leq|f(x)-g(y)| \leq 0.2$, which means that the economic development of Liaoning province is better than the environmental carrying capacity by a small amount, which indicates a great relevance between the results and the economic and environmental development policy of Liaoning province. As the old industrial base in northeast of China, at the beginning of Chinese economic reform, Liaoning province pursued the development of heavy industry on one side, which led to some negative impacts on the environment. As a result, people began to realize the importance of environmental protection. During the "ninth five-year plan" period, both environmental protection and heavy industry management work had achieved initial success, especially between 2001 and 2002, during China's admission to the World Trade Organization. The government increased environmental investments, which was good for economic diversification and industrial restructuring. In 2008, China successfully hosted the Olympic Games, and the government increased investment for environmental management work and promoted the development of tourism. The steady development of the tourism industry brought new heights to economic development in Liaoning province. The economic development of Liaoning province was kept in step with environmental protection and formed a positive cycle. Between 2009 and 2010, the economy and environment of Liaoning province gradually entered the sustainable development stage, in which Liaoning province developed a recycling economy and protected the ecological environment. The degree of economic and environmental coordinated development had risen steadily.

(3) Analyzing $D_{\mathrm{EECD}}$ of 14 cities: the overall trend has been rising steadily with occasional fluctuations. First, Dalian and Shenyang entered the senior concordance development condition early and since 2004 always rank near the top among 14 cities. As the most important old industrial base in the northeast, Dalian and Shenyang play a positive role for other cities of Liaoning province. Industrial restructuring and economic strength enhancement provide a strong support for the improvement of environmental quality. Secondly, several cities have a rapidly rising speed and wide range of $D$-values. For example, Yingkou's $D_{\text {EECD }}$ increases from 0.32 to 0.97 in 2005 and it has been in the senior concordance development condition since 2005; Huludao's $D_{\mathrm{EECD}}$ increases from 0.41 to 0.76 in 2003; Chaoyang's $D_{\mathrm{EECD}}$ increases from 0.72 to 0.93 in 2006; and Panjin's $D_{\mathrm{EECD}}$ increases from 0.77 to 0.97 in 2009 as a result of the new city development policy. Panjin plans to build a new coastal ecological city, adjust the city administrative districts and put a development layout scientifically in time, which promotes the coordinated development of economy and environment. Finally, the overall $D_{\mathrm{EECD}}$ of Dandong is lower.

3.2. Spatial Autocorrelation Analysis. Local spatial autocorrelation takes every local unit as the target item and can reveal the similarity and correlation among a local unit and the adjacent ones. It can also identify spatial agglomeration and spatial isolation and detect spatial heterogeneity. Local indicator of spatial association (LISA) is the most commonly used in local spatial autocorrelation. "High-High" means there is a conglomeration effect of high value among one region and the adjacent areas; "Low-Low" means; there is a conglomeration effect of low values. In each, the attributes of adjacent areas are inclined to be consistent with each other. However, "High-Low" and "Low-High" mean that the attributes of adjacent regions are in great disparity with each other [26, 27]. By using common LISA tools supported by GeoDa, a local spatial autocorrelation analysis was performed and the results are shown in Figure 4. "High-High" and "LowLow' mean that the city itself and the adjacent areas all have high and low $D_{\mathrm{EECD}}$, respectively, and the spatial difference among them is not obvious. "Low-High" means the city itself has low $D_{\mathrm{EECD}}$ while $D_{\mathrm{EECD}}$ in the adjacent areas is high, and the spatial difference among them is obvious. "HighLow" means the city itself has high $D_{\mathrm{EECD}}$ while $D_{\mathrm{EECD}}$ in the adjacent areas is low and again, the spatial difference is obvious. Others are "not significant," which means that provinces here did not meet the significance test.

As Figure 4 shows, in 1996, Dandong, Yingkou, and Huludao belong to the "High-Low" type. In 1997, Dalian belongs to the "High-Low" type. In 2000 and 2002, Dandong belongs to the "Low-High" type. In 2004, Dandong belongs to the "Low-High" type. Huludao belongs to the "High-Low" type. In 2005, Dandong belongs to the "Low-High" type. Chaoyang belongs to the "Low-Low" type. In 2009, Fushun 

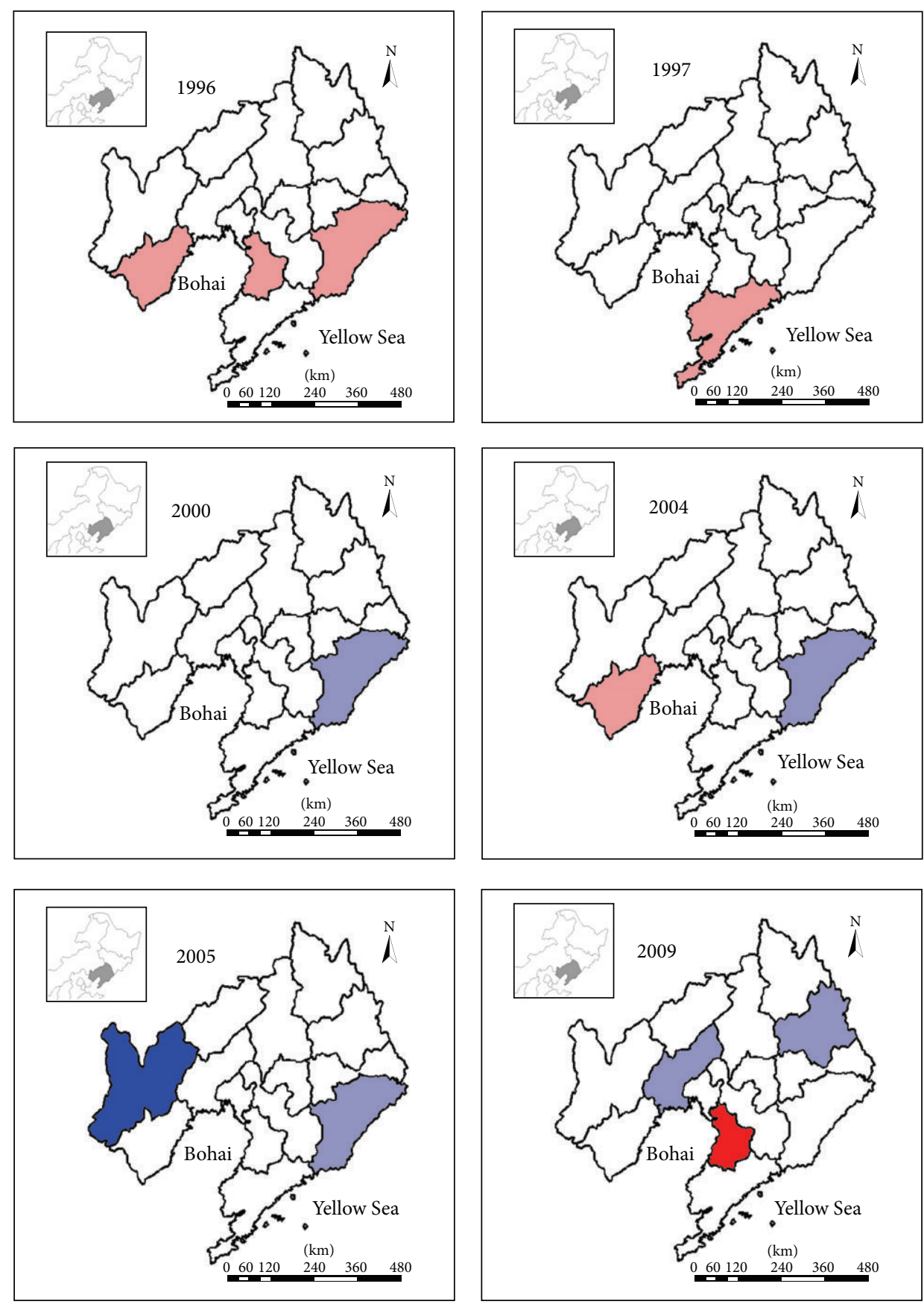

High-High

Low-High

Low-Low

High-Low

FIGURE 4: LISA cluster map for the economic and environment coordination development degree of intercity in Liaoning province.

and Jinzhou belong to the "Low-High" type. Yingkou belongs to the "High-High" type. To sum up, $D_{\mathrm{EECD}}$ of Liaoning province not only shows the development evolution trend of some cities themselves, but also could reflect whether the development speed between the city and the adjacent cities is correlated or not.

As Figure 4 shows, the evolution trend of Dandong is the most significant one among the 14 cities and especially declined from the "High-Low" type in 1996 to a "LowHigh" type surrounded by higher coordinated development degree cites. In other words, the economic and environmental coordinated development condition of Dandong falls and its development speed is slower than that of the adjacent city, a trend the government should pay attention to. Dandong has several special geographical features. It is located along a river, the coast, and the border with North Korea. Dandong 
is also the biggest border city in China. From the perspective of regional cooperation, Dandong has a strong geographic economic advantage. At the beginning of Chinese economic reform, Dandong won the title of "national top ten star industrial city." Since Chinese economic reform began, the geopolitical environment in North Korea has had a negative effect on Dandong economic development and market reforms [28]. In addition to external geopolitical factors, there are several factors restricting the economic and environmental coordinated development of Dandong. For example, the industrial structure of Dandong is not perfect, and the industrial pollution control is not adequate.

In 1996 and 2004, Huludao belonged to the "High-Low" type. The $D_{\mathrm{EECD}}$ is higher than that of the adjacent areas and it has a good demonstration effect on the adjacent cities. Huludao put off the construction of the new district, made a series of new policies, and invested more capital to upgrade environmental protection. Like "the fashion city" of Dalian, Huludao paid more attention to increasing the rate of green coverage and strengthening management of air quality. At same time, it required the refinery and oil factories to use advanced "antipollution" equipment to recycle waste gas. Huludao, as "the first admission city for Shanhaiguan" has been given a lot of policy support by the Chinese government, including building convenient transportation and developing tourism projects. The construction of costal city provides a strong support for the Huludao's environment improvement.

Yingkou rises from the "High-Low" type in 1996 to the "High-High" type in 2009. The condition of economic and environmental coordinated development has been rising all the time. Even as the economic and environmental coordinated development of the adjacent cities increased, Yingkou remained a high gathered city, which indicates that the regional $D_{\mathrm{EECD}}$ of Yingkou is very high. In part this is due to the government placed an great importance attached to city environmental protection in recent years. During the "eleventh five-year plan," the government emphasized green forestation and strove to create a natural "oxygen bar." At the same time, Yingkou also emphasized combing the city environment and the ecological environment by avoiding excessive urban spread and making efforts to expand the city green covering. The improvement of environmental quality promotes the economic development, and the coordination of the economy and the environment accelerates.

In 2005, Chaoyang belonged to the "Low-Low" type. Its degree of space discreteness is high, and the $D_{\mathrm{EECD}}$ of the adjacent cities is low. Chaoyang is located in the western industrial zone of Liaoning province. Relatively, the overall quality of economy and environment is backward. In 2009, Jinzhou and Fushun belonged to the "Low-High" type. As an important locale of heavy industry in Liaoning province, Jinzhou is located in the Bohai economic circle. The old town is relatively small and they have heavy pollution. Environmental improvement and investment are insufficient, which have adversely affected the region's economy and environment coordinated development.

Using measures of spatial dimension, this study analyzes the economic and environmental coordinated developmental condition of Liaoning province during 1996-2010. We find that the high value city of coordinated development degree changes from a scattering in Liaoning province to a clustering in middle-south of Liaoning province, which located in the Liaodong peninsula: south to the coastal economic zone, and Dalian is the center of this area; north extending to the central urban agglomeration of Liaoning province, and its center is Shenyang, including Anshan, Fushun, Benxi, Liaoyang, and Tieling; east to the railway (highway) of Shenyang-Dandong; and west to the south of the railway (highway) of Yelin et al. [23]. The best cities for economic and environmental coordinated development are Dalian and Shenyang. Huludao emphasizes environmental improvement, Panjin develops relying on the ecological planning policy, and Yingkou improves continuously. The three of them belong to spatial agglomeration cities, and their economic and environmental development speed exceed those of the surrounding cities. They not only have a huge potential for development among the cities of Liaoning province, but also play a leading role in the economic and environmental coordinated development. In contrast, the $D_{\mathrm{EECD}}$ of Dandong and Jinzhou is decreasing, and the $D_{\mathrm{EECD}}$ of the northwest is lower, especially in Chaoyang and Fuxin.

\section{Conclusions}

Through analyzing the spatiotemporal $D_{\mathrm{EECD}}$ of 14 cities in Liaoning province, we find the following In the temporal dimension, the $D_{\mathrm{EECD}}$ of Liaoning province has a significant rising trend. This indicates that the economy and environment coordinated development of Liaoning province has improved steadily from a serious disorder recession stage (the "ninth five-year plan" period) to a moderate concordance development stage ("tenth five-year plan" period) and finally reaches a senior concordance development stage ("tenth five-year plan" period). The overall development of Liaoning province is better and improving. In the spatial dimension, the high value city of coordinated development degree changes from a scattering in Liaoning province to a clustering in the middle-south of Liaoning province. The $D_{\text {EECD }}$ of northwestern area is lower, mainly in Chaoyang and Fuxin. With "the opening-up of the coastal economic zone in Liaoning province" becoming a national and macroscopic strategic goal, the coastal economic zone of Liaoning province, including Dalian, Dandong, Jinzhou, Yingkou, Panjin, and Huludao promoted the development of the west coastal areas. The northwest region should accelerate the coordinated development between economic restructuring and the ecological protection to further enhance comprehensive economic strength in the range of environmental carrying capacity of Liaoning province.

\section{References}

[1] H. Wang, L. L. Guo, and L. Song, "A quantitative study on the coordination degree between economy and environment in Liaoning Province," Progress in Geography, vol. 29, no. 4, pp. 463-470, 2010.

[2] H. Wang and B. Jiang, "A quantitative study on the coordinated development of costal city's ecological environment and tourist 
economy," Journal of Arid Land Resources and Environment, vol. 5, no. 22, pp. 75-78, 2006 (Chinese).

[3] G. Z. Qiao and X. Liu, "Study on the difference of cities environment quality of Liaoning Province," Territory \& Natural Resources Study, no. 2, pp. 70-71, 2009 (Chinese).

[4] H. Wang, L. L. Guo, and L. Song, "Spatial evolution of the economic and environmental coordination degree for 14 cities in Liaoning Province," Journal of Arid Land Resources and Environment, vol. 25, no. 5, pp. 35-40, 2011 (Chinese).

[5] S. H. Yang, Urban Ecological Environmental Science, Science Press, Beijing, China, 2003, Chinese.

[6] Z. B. Wang, G. L. Fang, S. W. Cheng, and J. Wang, "Evolution of coordination degree of eco-economic system and early-warning in the Yangtze River Delta," Journal of Geographical Sciences, vol. 23, no. 1, pp. 147-162, 2013.

[7] H. Wang, J. G. Lin, and B. Jiang, "Analysis on the coordination development degree of tourism and environment in Dalian," Marine Environmental Science, vol. 25, no. 1, pp. 84-87, 2006 (Chinese).

[8] H. W. Yin and F. H. Kong, "Analysis of the coordination degree between economic development and environment in Shandong Province," Human Geography, vol. 20, no. 2, pp. 30-33, 2005 (Chinese).

[9] W. Tobler, "A computer movie simulating urban growth in the Detroit Region," Economic Geography, vol. 46, pp. 234-240, 1970.

[10] T. H. Keitt, O. N. Bjørnstad, P. M. Dixon, and S. Citron-Pousty, "Accounting for spatial pattern when modeling organismenvironment interactions," Ecography, vol. 25, no. 5, pp. 616625, 2002.

[11] D. J. Brus and J. J. de Gruijter, "Using nonprobability samples in design-based estimation of spatial means of soil properties," in Proceedings of the 4th International Symposium on Spatial Accuracy Assessment in Natural Resources and Environmental Sciences (Accuracy '00), vol. 2000, pp. 83-90, 2000.

[12] L. Anselin, Spatial Econometrics: Methods and Models, Kluwer Academic, 1998.

[13] W. Guan and H. F. Zhu, "Spatio-temporal analysis of intercounty economic difference in Liaoning Province based on ESDA," Geographical Research, vol. 11, no. 30, pp. 2009-2016, 2011 (Chinese).

[14] D. C. Wang and T. S. Yang, "Analysis on transformation path of economic development mode in Liaoning province," Journal of Shenyang University of Technology, vol. 10, no. 4, pp. 1-5, 2012 (Chinese).

[15] K. M. Zhang, Z. G. Wen, B. Du et al., The City's Ecological Evaluation and Index System, Chemical Industry Press, Beijing, China, 2003, Chinese.

[16] M. Zhang, Regional Tourism Competitiveness Theory and Empirical Research, Southwest University of Finance and Economics University Press, Chengdu, China, 2005, Chinese.

[17] J. H. Xu, Mathematical Method in Modern Geography, Advanced Education Press, Beijing, China, 2002, Chinese.

[18] S. H. Yang, "A study on the forecast and regulation of coordination development of urban environment and economy in Guangzhou," Geographical Since, vol. 14, no. 2, pp. 136-143, 1994 (Chinese).

[19] J. Aldstadt, "Spatial clustering," in Handbook of Applied Spatial Analysis: Software Tools, Methods and Applications, pp. 279-300, Springer, 2010.
[20] P. A. P. Moran, “The interpretation of statistical maps," Journal of the Royal Statistical Society B, vol. 10, no. 2, pp. 243-251, 1948.

[21] P. A. Moran, "Notes on continuous stochastic phenomena," Biometrika, vol. 37, no. 1-2, pp. 17-23, 1950.

[22] L. Anselin, "Local indicators of spatial association-LISA," Geographical Analysis, vol. 27, no. 2, pp. 93-115, 1995.

[23] Y. L. Fang, Z. F. Huang, K. Wang, and W. Tu, "Spatial and temporal analysis of Chinese provincial tourism economy based on PCA-ESDA," Economic Geography, vol. 832, no. 8, pp. 149154, 2012 (Chinese).

[24] A. Getis and J. K. Ord, "The analysis of spatial association by the use of distance statistics," Geographical Analysis, vol. 24, no. 3, pp. 189-240, 1992.

[25] Y. C. Ma and L. Q. Lanqun, "Application and comparison of examining methods of the data average and the standard $\mathrm{t}$ value," Hebei Metallurgy, no. 2, pp. 44-56, 2010 (Chinese).

[26] S. Q. Wei, J. Q. Zhang, and J. F. Chen, "Study on construction land distribution in Fujian and Taiwan provinces based on spatial autocorrelation analysis," Progress in Geography, vol. 26, no. 3, pp. 11-17, 2007 (Chinese).

[27] B. Meng, J. F. Wang, W. Z. Zhang et al., "Evaluation of regional disparity in China based on spatial analysis," Scientia Geographica Sinica, vol. 25, no. 4, pp. 393-400, 2005 (Chinese).

[28] L. Zhang and J. Z. Cao, "How to optimize geographical economic environment in dandong," Journal of Eastern Liaoning University, vol. 6, no. 2, pp. 167-171, 2011 (Chinese). 

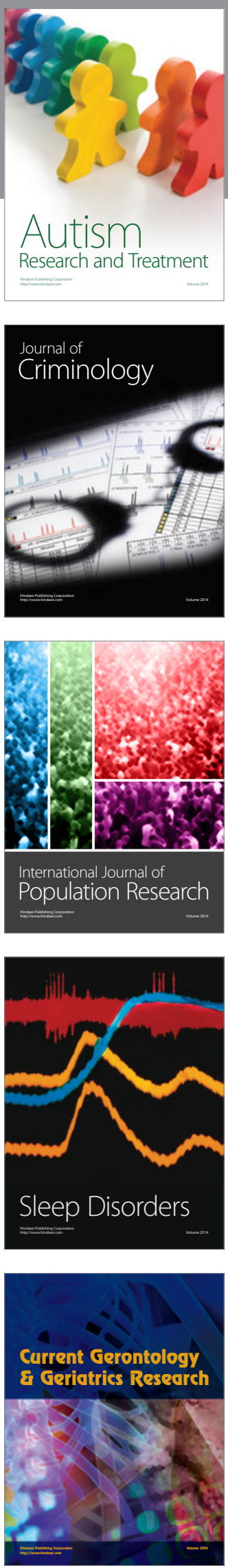
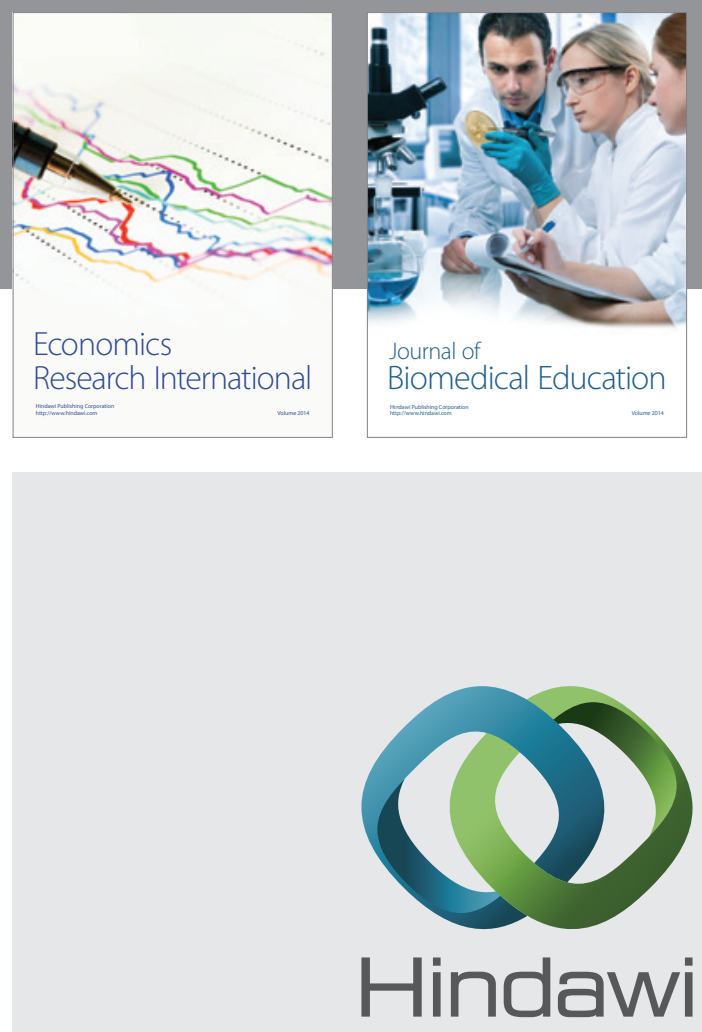

Submit your manuscripts at

http://www.hindawi.com
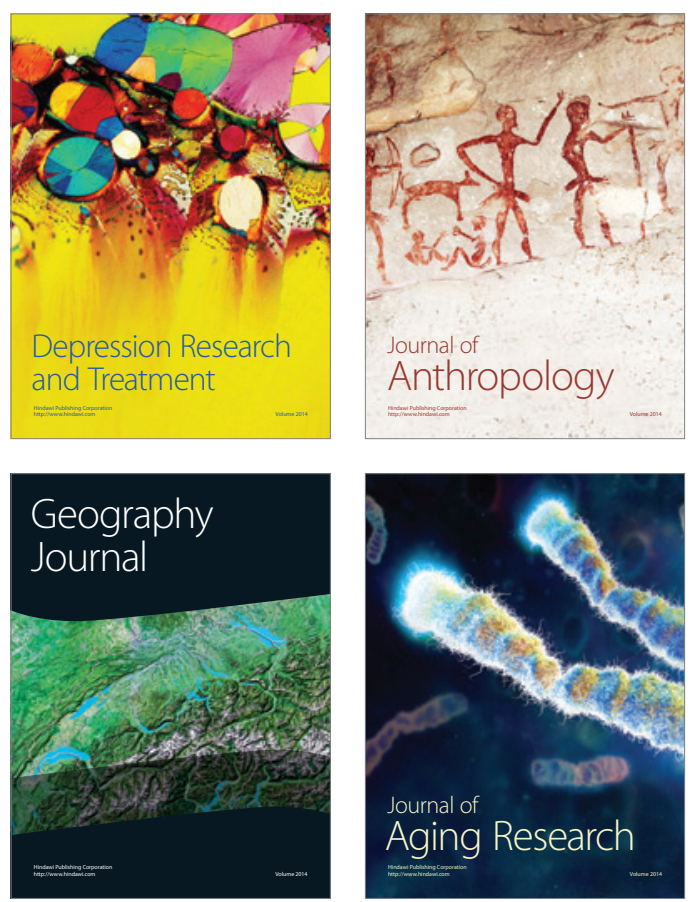
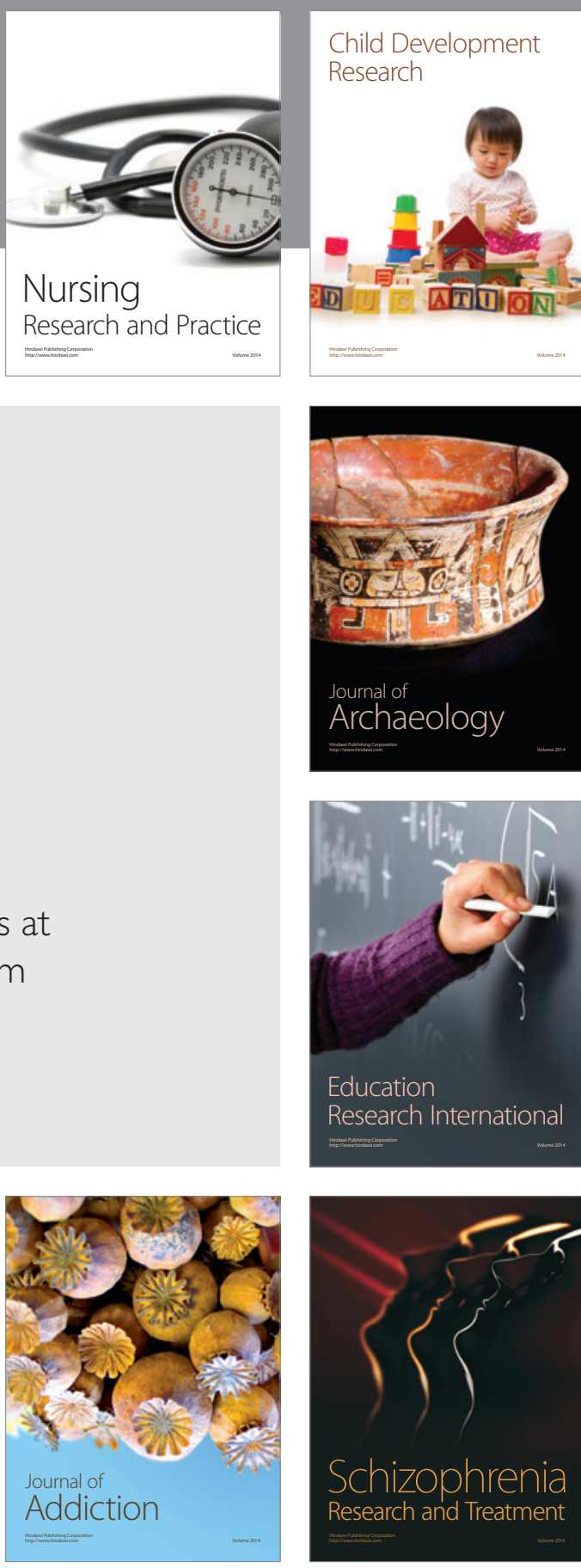

(D)
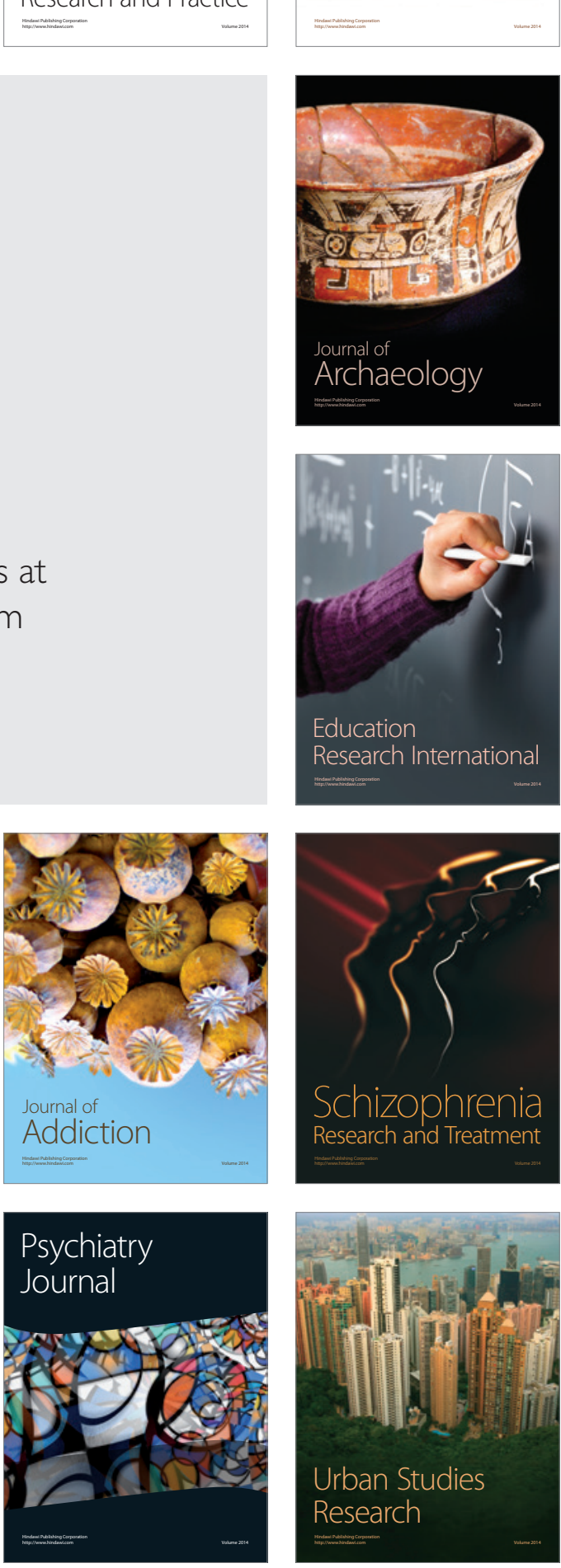